\title{
Modulation of infusion processes to obtain coffee-derived food ingredients with distinct composition
}

\author{
Guido R. Lopes ${ }^{1} \cdot$ Cláudia P. Passos $^{1} \cdot$ Carla Rodrigues $^{2} \cdot$ José A. Teixeira $^{3} \cdot$ Manuel A. Coimbra $^{1}$
}

Received: 24 April 2019 / Revised: 30 May 2019 / Accepted: 9 June 2019 / Published online: 24 June 2019

c) Springer-Verlag GmbH Germany, part of Springer Nature 2019

\begin{abstract}
Coffee infusion experiments were conducted to infer how operational variables (time, temperature, mass to volume ratio, and grinding) might affect the efficiency and/or selectivity of compounds extraction. Although the different variables have extensively been reported independently, to the best of our knowledge, no experimental design was yet delineated to study the simultaneous effect of variables in coffee composition. This study fulfills this gap by constructing surface models that reflect the responses in a wide-ranging design space. The freeze-dried extracts were compared regarding the overall yield of extraction, carbohydrate content and composition, caffeine, chlorogenic acid (5-CQA) content, color, and viscosity. Temperature was the major factor for coffee extracts differentiation, regarding both overall and carbohydrates yield and composition. The extraction process efficiency is more related to galactomannans extraction than arabinogalactans. Varying operational conditions, coffee extracts with distinct chemical properties are obtained from the same roasted coffee, broadening their applications in food formulations.
\end{abstract}

\section{Graphic abstract}
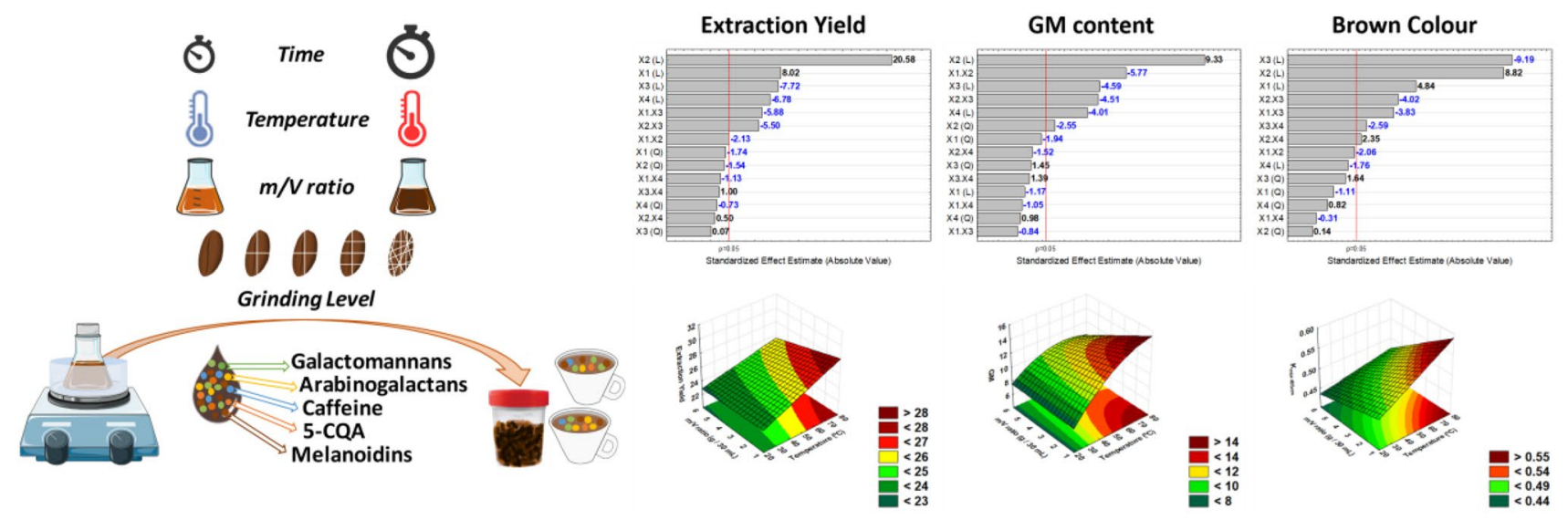

Keywords Carbohydrates $\cdot$ Polysaccharides $\cdot$ Caffeine $\cdot$ Chlorogenic acids $\cdot$ Response surface methodology $\cdot$ Extraction process

Electronic supplementary material The online version of this article (https://doi.org/10.1007/s00217-019-03318-9) contains supplementary material, which is available to authorized users.

Manuel A. Coimbra

mac@ua.pt

Extended author information available on the last page of the article

\section{Introduction}

Coffee brews are among the most consumed and appreciated beverages in the world. Their properties and quality rely on the intrinsic properties of the green coffee beans, roasting process, and methods of preparation [1-3]. Coffee species exhibit different compounds composition regarding carbohydrates, 
caffeine, and chlorogenic acids that affect the physicochemical characteristics of the coffee powder used for extraction and, consequently, the coffee brew [2]. However, the roasting process also exerts a great effect and is responsible for the increased extractability of coffee carbohydrates $[4,5]$. Moreover, for the extraction of compounds from roasted coffee beans, they must be grounded, breaking the matrix, and making the compounds accessible for extraction when in contact with water. The degree of grinding used, from coarser to finer particles, affects the extraction rate due to the different surface area available or the porosity between the coffee particles which defines the water flow during coffee percolation $[2,6]$.

Several reports have been trying to find the influence of operational parameters, one-by-one, on different coffee brews properties and/or compare the composition of the coffee brews prepared with different methods [1, 7-11]. However, there are so many variables that the uniformity of conditions and results are difficult to achieve in this way. Mathematical modeling through physical-engineering approaches has been useful for the understanding of the coffee extraction processes [12-15]. However, these models did not reflect the composition obtained through the variation of the different extraction conditions. Response surface methodologies are already used in the coffee field for the development and optimization of procedures for analysis of coffee volatiles [16] and extraction of oils or phenolic compounds from spent coffee grounds or coffee silverskin [17-19].

In this study, fulfilling the hypothesis that different operational variables provide extracts with different compositions and properties from the same roasted coffee beans, time and temperature of extraction, mass of coffee to volume of water ratio, and coffee grinding level were tested on their effect on the chemical composition of the brew (viewed as a freezedried coffee extract) obtained after extraction. The use of the same coffee for all experiments eliminates the variability related to roasting degree or coffee species. The intent is to comprehend how different extraction conditions affect the properties of coffee extracts in a fixed water volume to understand the variability that may be achieved regarding coffee compounds. Moreover, a statistical and holistic approach was used to infer the factors that affect the coffee extraction system, constructing significant models for modulation of the coffee extract characteristics. This approach will allow to obtain coffee extracts with the desired chemical properties regarding their use in new food formulations.

\section{Materials and methods}

\section{Coffee samples and chemicals}

A commercial blend of roasted coffee beans (Delta ${ }^{\circledR}$ Lote Chávena) was used to perform the coffee extraction experiments. The initial composition on carbohydrates, caffeine and 5-CQA content was determined in the ground coffee (Table 1), as well as the moisture content that was below 5\% all over the experiments (ISO 11817:1994).

\section{Grinding of coffee samples}

A coffee grinder (Flama-1231) was used to grind the roasted coffee beans. This equipment allows the selection of different grinding levels from finer (level 1) to coarser (level 3) particles. The particle size profile of the grounded samples was analyzed with a Malvern Mastersizer 2000 particle size analyser equipped with a Scirocco 2000 accessory (Supplementary Material Fig. S1).

\section{Solid-liquid extractions}

Solid-liquid extractions were performed using freshly grounded coffee according to the desired level of grinding and $30 \mathrm{~mL}$ of distilled water in a 100-mL Erlenmeyer flask covered and maintained in a water bath with magnetic agitation during the intended time and temperature. After the experiments, the flasks were cooled to room temperature and their content was vacuum filtrated (1.2- $\mu \mathrm{m}$ glass microfiber filter) with the retained material washed with an additional $30 \mathrm{~mL}$ of water. The filtrates were all frozen and freezedried. The extraction yields were determined by weight and the extracts were stored under an anhydrous atmosphere until characterization analyses.

\section{Single-factor coffee extractions}

Several experiments were performed varying only one factor (time, temperature, mass to volume ratio or grinding level), while the other three were maintained constant. The constant values for the different factors were: $30 \mathrm{~min}$ for time, $80{ }^{\circ} \mathrm{C}$ for temperature, $1 \mathrm{~g}$ per $30 \mathrm{~mL}$ for $m / V$ ratio, and the level 3 for the grinding level as presented in Supplementary Material Table S1.

\section{Central composite design}

The conditions used to study the main effects and interactions between the independent variables were settled based both on the results from single-factor results, as well as experimental limitations (avoiding high temperatures, as boiling water, and prolonged times) and/or new coffee trends as cold brews. An unreplicated $2^{4}$ full-factorial design to evaluate the effect of time $\left(X_{1}, \mathrm{~min}\right)$, temperature $\left(X_{2},{ }^{\circ} \mathrm{C}\right)$, mass to volume $(\mathrm{m} / \mathrm{V})$ ratio $\left(X_{3}\right.$, g per $\left.30 \mathrm{~mL}\right)$, and grinding level $\left(X_{4}\right)$ (Table 1) was used. Each factor has 2 levels$X_{1}(10$ and $360 \mathrm{~min}), X_{2}\left(20\right.$ and $\left.80{ }^{\circ} \mathrm{C}\right), X_{3}(1$ and $6 \mathrm{~g}$ per $30 \mathrm{~mL}$ ), and $X_{4}$ (level 1 and 3) - coded (+1) and (-1) for 


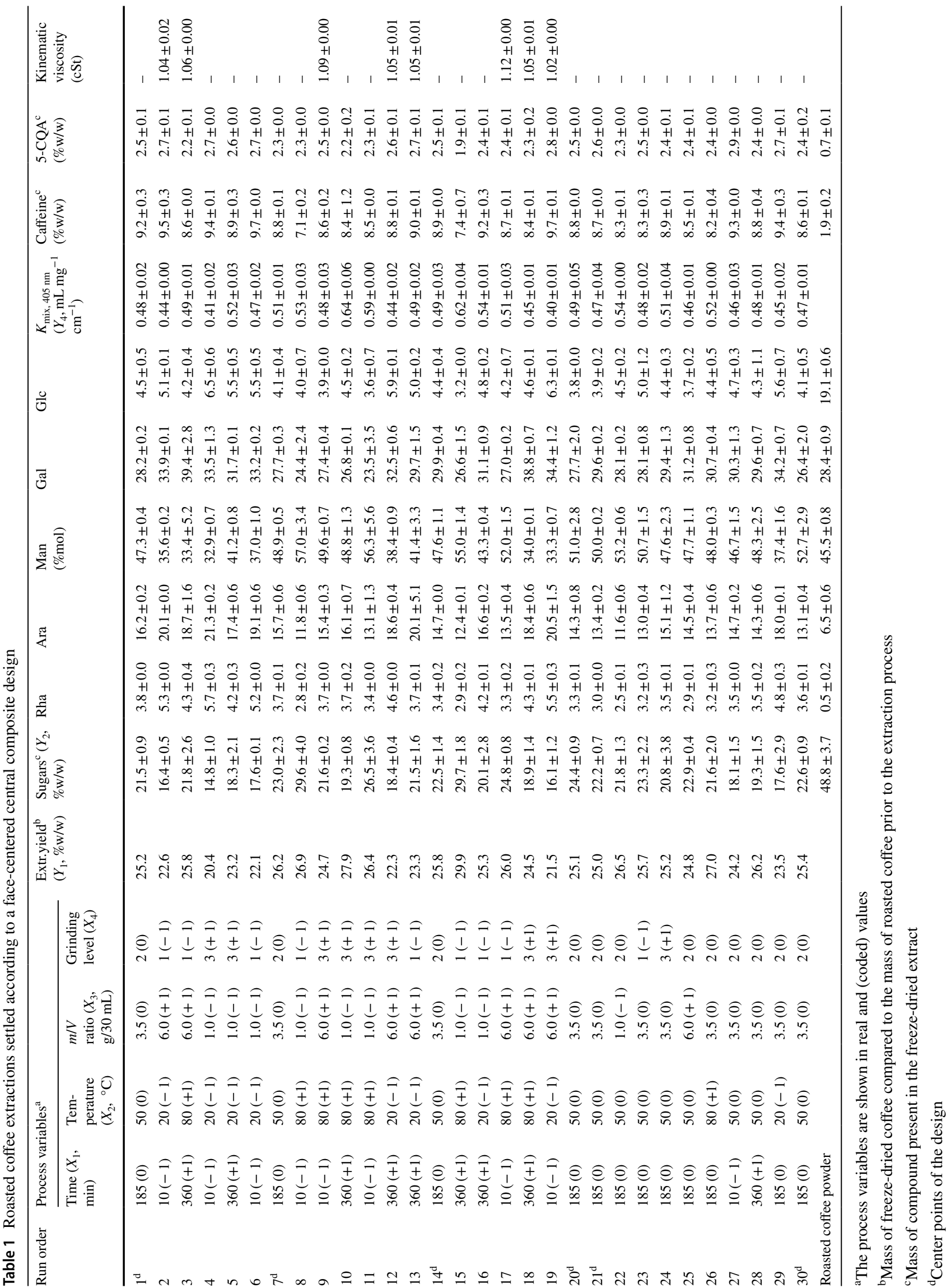


the higher and lower limits of each one, respectively. In a two-level full-factorial design, $2^{k}$ runs are required, where $k$ represents the number of factors to be analyzed, resulting in 16 experiments performed. Additionally, a center point with four replicates was tested to detect the presence of curvature in the responses, to measure the process variability/stability, and to estimate the pure error needed for the analysis of variance. The design was composed of a total of 20 runs that were performed randomly to avoid bias, minimizing the effect of uncontrolled variables. The initial $2^{4}$ full-factorial design was augmented with axial experiments to a face-centered central composite design (FCCD, $\alpha=1)$ allowing to estimate higher-order terms, namely quadratic terms once an inflation point related to curvature is detected in the design space. Thus, the additional axial ( 8 runs) and center points ( 2 runs) were performed to obtain models that better describe the system analyzed. The experimental data were fitted to a second-order response surface model represented by a quadratic polynomial equation given as,

$Y=\beta_{0}+\sum_{i=1}^{k} \beta_{i} x_{i}+\sum_{i=1}^{k} \beta_{i i} x_{i}^{2}+\sum_{i=1}^{k} \sum_{j=i+1}^{k} \beta_{i j} x_{i} x_{j}$,

where $Y$ is the response observed in the dependent factor of interest, $\beta_{0}, \beta_{i}, \beta_{i i}$ and $\beta_{i j}$ terms represent the constant, linear, quadratic, and two-factor interaction regression coefficients, respectively, while $x_{i}$ represents the independent variables in a dimensionless coded form. The dependent variables were: extraction yield $\left(Y_{1}, \% \mathrm{w} / \mathrm{w}\right)$, sugars content in the extract $\left(Y_{2}\right.$, $\% \mathrm{w} / \mathrm{w})$, galactomannans content in the extract $\left(Y_{3}, \% \mathrm{w} / \mathrm{w}\right)$, and $K_{\text {mix, }} 405 \mathrm{~nm}\left(Y_{4}, \mathrm{~mL} \mathrm{mg}^{-1} \mathrm{~cm}^{-1}\right)$. The different coefficients (main effects, interactions, and high-order effects) were found by analysis of variance (ANOVA) using 95\% significance level ( $p$ value). The Pearson's correlation coefficient $(r)$, with confidence level $p<0.05$, was used to describe the relationships among compounds. The experimental data were statistically analyzed using Statistica v12 and Minitab v17 softwares.

\section{Extracts characterization}

\section{Carbohydrates analysis}

The carbohydrates content of the freeze-dried extracts and the initial ground roasted coffee were evaluated through the sum of the amount of the individual sugars achieved after acid hydrolysis and derivatization to alditol acetates as described in Lopes et al. [20] (2 replicates, when the main sugars variability presented differences lower than $5 \%)$. The estimation of galactomannans (GM) can be performed by considering the mannose content plus the addition of $5 \%$ of the total amount of mannose that accounts for galactose content, assuming a degree of substitution of 1:20, meaning a substitution with single residues of galactose for every 20 residues of mannose in the main chain, i.e., a $5 \%$ degree of branching. This is in accordance with the degree of branching of GM (3-6\%) obtained from roasted coffee infusions prepared with different roasting degrees from distinct coffee species and also GM extracted from spent coffee grounds [21-24]. For the estimation of the content of arabinogalactans (AG), it was accounted the amount of galactose from which the galactose content was subtracted that is part of GM structure and the content of arabinose was added. Thus, it is assumed that all galactose was component of the AG (except an amount corresponding to 5\% of total mannose) and that all arabinose in the extracts was from AG.

\section{Caffeine and 5-CQA analysis}

The determination of caffeine and 5-caffeoylquinic acid (5-CQA) was performed using the freeze-dried coffee extracts by the preparation of aliquots of $10 \mathrm{mg} \mathrm{mL}^{-1}$ that were passed through $0.22-\mu \mathrm{m}$ filters prior HPLC injection ( 2 replicates). The runs were performed on a HPLC-DAD apparatus equipped with a C18 column (Waters Sherisorb S10 ODS2, $4.6 \mathrm{~mm} \times 250 \mathrm{~mm}, 10 \mu \mathrm{m})$ equilibrated with formic acid 5\% (eluent $\mathrm{A}$ ). The samples were eluted at a flow

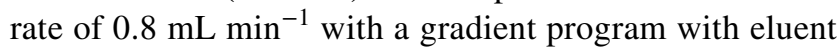
A and methanol as eluent B [25]. The caffeine peak was detected at $280 \mathrm{~nm}$ and for 5-CQA at $325 \mathrm{~nm}$. For quantification purposes, calibration curves of caffeine $\left(R^{2}=0.997\right)$ and 5-CQA $\left(R^{2}=0.993\right)$ were prepared.

\section{Brown color measurement: specific extinction coefficient $\left(K_{\text {mix }} 405 \mathrm{~nm}\right)$}

The specific extinction coefficient at $405 \mathrm{~nm}$ was determined using the freeze-dried coffee extracts. Several dilutions (0-1 $\mathrm{mg} \mathrm{mL}^{-1}$ in distilled water) were used to determine spectrophotometrically the coefficient at $405 \mathrm{~nm}$ that corresponds to the slope in a plot of absorbance versus concentration curve, giving $K_{\mathrm{mix}}, 405 \mathrm{~nm}$ [20, 26] (2 replicates).

\section{Viscosity measurements}

The viscosity measurements were performed in a Cannon-Fenske routine viscometer (Size 50) with the freezedried extracts from the runs where higher mass was used $(6 \mathrm{~g}$ per $30 \mathrm{~mL})$. The coffee extracts samples $\left(30 \mathrm{mg} \mathrm{mL}^{-1}\right)$ were kept in a thermostatic water bath that maintained the temperature at $25.00 \pm 0.01{ }^{\circ} \mathrm{C}$. The efflux time was measured in triplicate with an electronic digital stopwatch (0.01 s). The kinematic viscosity values were obtained multiplying the efflux time by the constant value provided by the manufacturer for that viscometer. 


\section{Results and discussion}

\section{Extraction yield}

The single-factor experiments of coffee extraction process showed that when varying the temperature, the range of values $(7.2 \%$, between the minimum and maximum) was higher than for the other factors studied $(2.1,1.9$, and $1.6 \%$ for time, $m / V$ ratio or grinding level, respectively) at a defined temperature $\left(80^{\circ} \mathrm{C}\right.$ ) (Supplementary Material Table S1). Longer extraction times and temperature increase the extraction of coffee compounds, which also occurs with lower $m / V$ ratio and finer particles associated with the lower level of grinding. These results agree with several studies regarding infusion-type extraction methods, as well as brews as espresso coffee, that deal with shorter extraction times [7-10,14]. As the single-factor experiments do not allow the determination of the combined effects for the factors or independent variables, a wide range of conditions were used. The higher level of temperature $\left(80^{\circ} \mathrm{C}\right)$ was selected to avoid the loss of solvent and pressure problems, related to a closed system when using higher extraction times. The higher level of time was selected $(6 \mathrm{~h})$ according to the literature, as the increase of the extraction time for more than $5-10 \mathrm{~h}$ is not reported to increase the extracted solids for coffee brew [12]. Moreover, coffee cold brews extraction methods were associated with prolonged extraction times (6 or more $h$ ) $[27,28]$. Indeed, the lower level of temperature was chosen considering the lack of characterization, namely concerning carbohydrates content and composition, related to the coffee cold brews that has gained attention in the last years. The extraction yield ranged from 20.4 to $29.9 \% \mathrm{w} / \mathrm{w}$ among all conditions studied. These results are in accordance to literature, where extraction yield ranges from 18 to $32 \%$, depending on the method of coffee extraction used $[1,9,29]$. Considering the runs of the central composite design, the mass of freeze-dried extract and the volume of water used in the experiments $(30 \mathrm{~mL})$, the coffee solution after filtration process had $6.8-52.0 \mathrm{~g} \mathrm{~L}^{-1}$ of total solids (204-1560 $\mathrm{mg}$ per cup). The range of values for the different brewing methods $\left(10.3-55.7 \mathrm{~g} \mathrm{~L}^{-1}\right)$ found in literature $[1-3,9,20,28]$ is in accordance with the results obtained in the present study. The solids concentration in the brew or filtrate obtained $(0.7-4.9 \% \mathrm{w} / \mathrm{w})$ is relatable to diluted home brewing processes and is quite far away from high concentration of soluble solids $(15-25 \% \mathrm{w} / \mathrm{w})$ obtained in the final extracts of industrial coffee extraction processes [29]. These results suggest that applying an infusion extraction procedure and modulating the extraction parameters, different extraction yields and total solids concentrations can be achieved, with comparable results to the different homemade coffee brews. Pareto chart (Fig. 1a) represents the effects on extraction yield that are statistically significant (at 95\% confidence level) as the ones beyond the vertical plotted line with the length of the bars proportional to the standardized effect in the model.

Figure 1a shows that the linear terms of all variables $\left(X_{1}-X_{4}\right)$ exhibit significant effect on coffee extraction yield, which does not happen when considering the quadratic terms. However, Pareto chart evidences that linear temperature term exerts clearly the most preponderant (explained $59 \%$ of the variability observed) and positive effect, with time, $m / V$ ratio, and grinding level linear terms with a quite similar influence. Time had a positive effect, meaning that the longer the extraction, the higher the extraction yield, while the $m / V$ ratio and grinding level exhibit a negative effect (i.e. higher ratio leads to lower extraction yield and the coarser the coffee particles the lower the extraction yield). The $m / V$ ratio effect is elucidated once water becomes more saturated and with decreasing ability to extract more compounds. The grinding level may influence the percolation of water through coffee cake or the extraction of compounds due to the variation of surface area of the particle $[2,6]$. Once in this experiment the particles were in contact with the water, without the formation of a coffee cake, the effect regarding grinding is related to the extraction surface area of contact and the diffusion phenomena. The increase of fines, damaged cells, and smaller particles increases the extraction of solids through the reduction of the mass transfer resistance [12].

The grouping of all runs regarding the temperature effect shows a clear distinction between the levels studied: $20.4-25.3 \% \mathrm{w} / \mathrm{w}\left(20^{\circ} \mathrm{C}\right), 24.2-26.5 \% \mathrm{w} / \mathrm{w}\left(50{ }^{\circ} \mathrm{C}\right)$, and $24.5-29.9\left(80^{\circ} \mathrm{C}\right)$. However, it also shows similar extraction yields, regardless of the temperature used, i.e., extraction at $20{ }^{\circ} \mathrm{C}$ with higher extraction yield than some experiments performed at $50{ }^{\circ} \mathrm{C}$ or $80{ }^{\circ} \mathrm{C}$. Thus, with all temperatures, equal extraction yields may occur. However, this is based only on the extraction yield, i.e., considering that the extract composition obtained is barely the same in all conditions. For the remaining variables, a greater dispersion was verified for the grouped values due to the greater influence of temperature over the other factors. Pareto chart (Fig. 1a) also shows as significant two 2-way interactions: the terms $X_{1} \cdot X_{3}$ and $X_{2} \cdot X_{3}(p<0.05)$; and marginally the term $X_{1} \cdot X_{2}$ $(p=0.0505)$ (Supplementary Material Table S2). When an interaction is significant, it means that the effect of a term on the response is distinct at different levels of another independent variable. Thus, the analysis of significant interactions indicates that the effect of $m / V$ ratio is dependent on the level of time and temperature, being more significant when using longer times and higher temperatures (3D Surface plots in Supplementary Material Fig. S2). The experimental data for coffee extraction yield fit a full quadratic 
(a) Extraction Yield $\left(Y_{1}, \% w / w\right)$

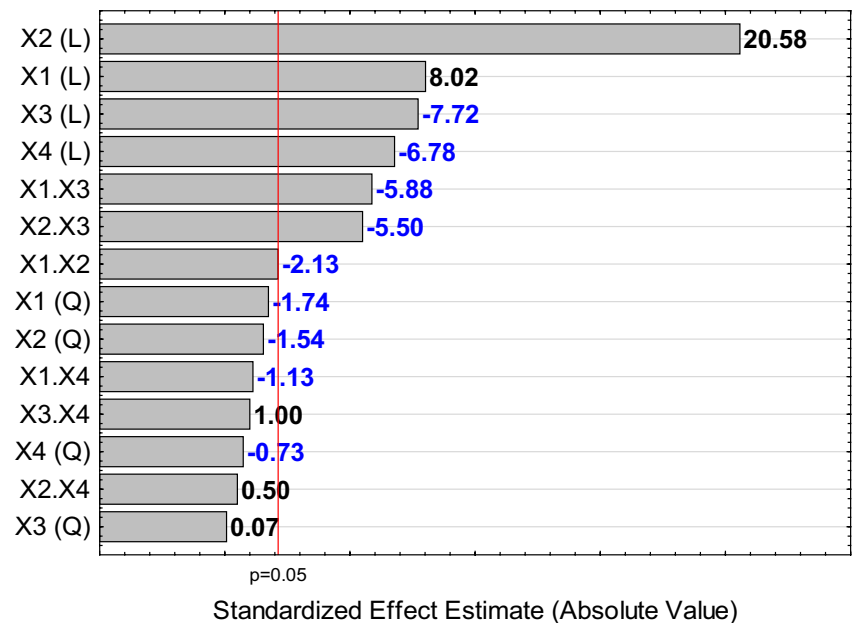

(c) GM content $\left(Y_{3}, \% \mathrm{w} / \mathrm{w}\right)$

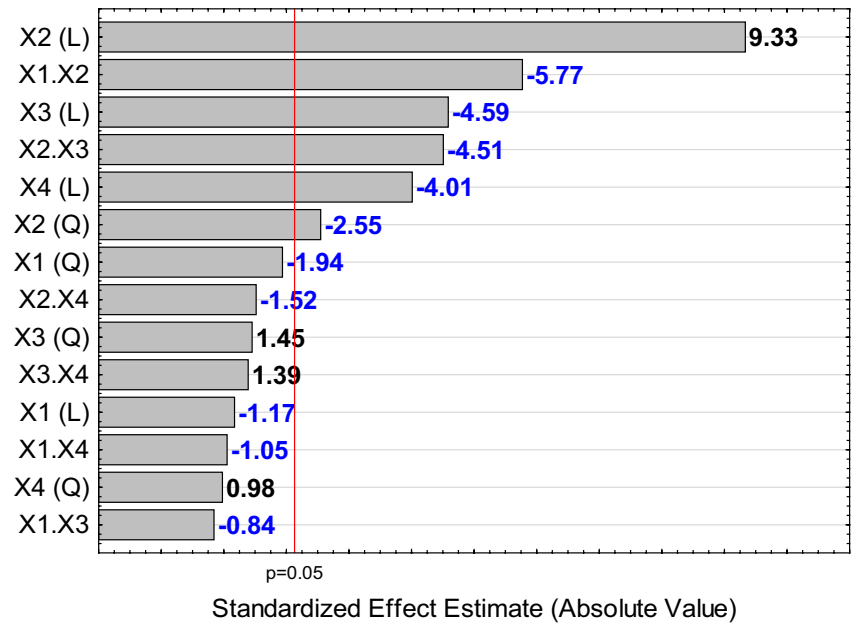

Fig. 1 Pareto chart for the effects of time $\left(X_{1}\right)$, temperature $\left(X_{2}\right)$, $m / V$ ratio $\left(X_{3}\right)$, and grinding level $\left(X_{4}\right)$ during the coffee extraction experiments on the a extraction yield $\left(Y_{1}, \% \mathrm{w} / \mathrm{w}\right)$, b sugars content in the extract $\left(Y_{2}, \% \mathrm{w} / \mathrm{w}\right)$, c galactomannans content in the extract $\left(Y_{3}, \% \mathrm{w} / \mathrm{w}\right)$ and $\mathbf{d} K_{\text {mix, }} 405 \mathrm{~nm}\left(Y_{4}, \mathrm{~mL} \mathrm{mg}^{-1} \mathrm{~cm}^{-1}\right)$. The negative

model able to explain nearly $98 \%$ of the variability occurred in the system $\left(R^{2}=0.98\right)$ with a non-significant lack-of-fit, meaning a close agreement between the experimental data and the results predicted by the model. The non-significant terms were removed to simplify/reduce the model (Supplementary Material Table S2). Thus, the data fit a reduced but significant $(p<0.0001)$ linear model for extraction yield with a high determination coefficient $\left(R^{2}=0.92\right)$ and high predictive ability $\left(R^{2}=0.85\right)$, as presented in Table 2 .

\section{Sugars content}

Polysaccharides constitute a considerable fraction of roasted coffee beans and coffee brews $[4,5]$. Only the (b) Sugars Content $\left(Y_{2}, \% \mathrm{w} / \mathrm{w}\right)$

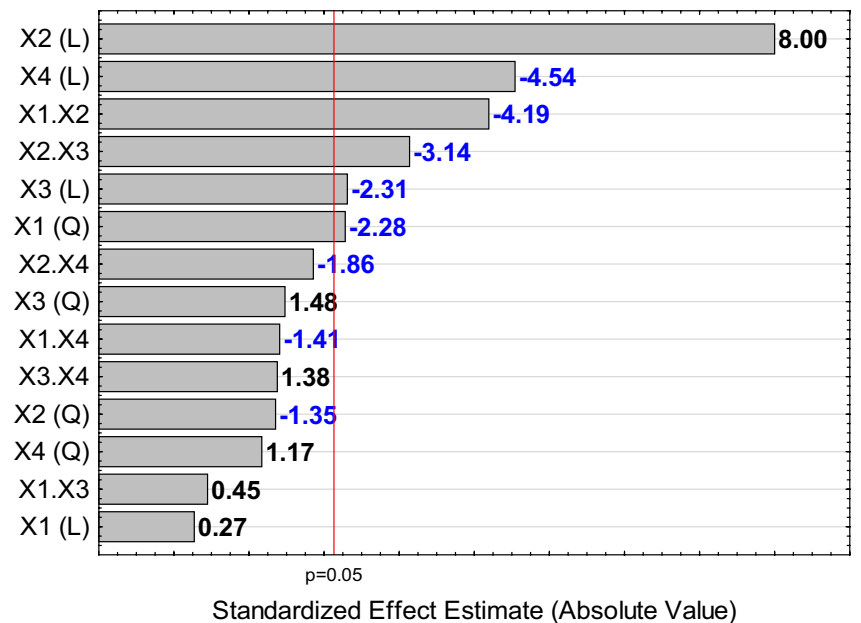

(d) $K_{\text {mix }, 405 \mathrm{~nm}}\left(Y_{4}, \mathrm{~mL} \mathrm{mg}^{-1} \mathrm{~cm}^{-1}\right)$

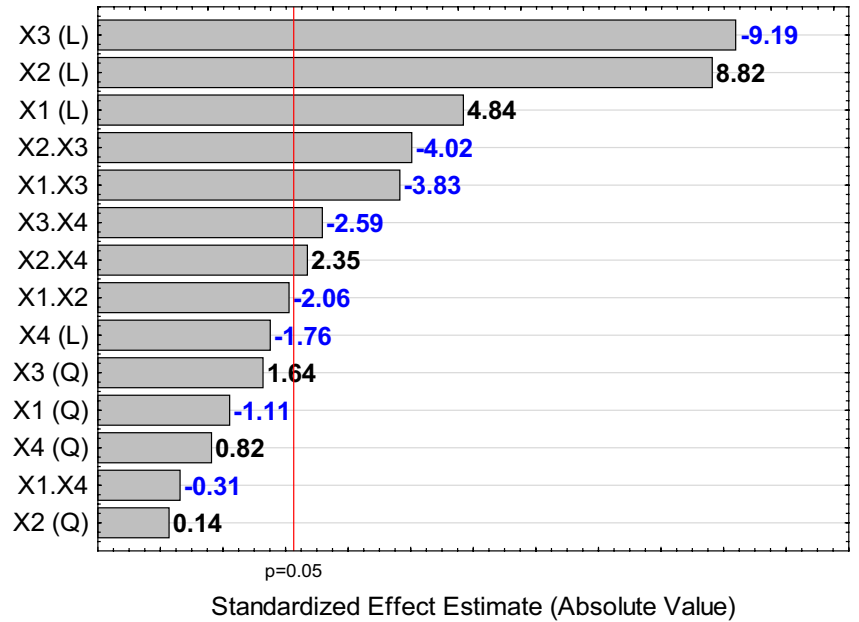

and positive effects are highlighted in blue and black, respectively. $L$ and $Q$ represent the linear and quadratic effects, respectively. The region (right side) of statistical significance ( $95 \%$ confidence level) is defined by the vertical line

drastic extraction conditions used in industrial soluble coffee processing are able to degrade the polysaccharides [29]. Thus, the analysis performed is a valid estimation of carbohydrate content of the coffee brews, once the extraction conditions used in this experiment are presumably unable to degrade coffee polysaccharides. The singlefactor experiments (Supplementary Material Table S1) point out that the factor that seems to exhibit higher preponderance for carbohydrates content in coffee extracts is temperature, with a range of variation of $12 \%$ when compared to $3-7 \%$ from the other experiments. The study of the central composite design shows that the sugars content of coffee freeze-dried extracts varied from 14.8 to $29.7 \% \mathrm{w} / \mathrm{w}$, a twofold increase from minimum to maximum 
Table 2 Models developed for the description of the variation in dependent variables ( $Y_{1}$ - extraction yield, $Y_{2}$-sugars, $Y_{3}$ - galactomannans and $Y_{4}-K_{\text {mix, }} 405 \mathrm{~nm}$ ) as function of the parameters studied
( $X_{1}$-time, $X_{2}$-temperature, $X_{3}-\mathrm{m} / \mathrm{V}$ ratio, and $X_{4}$-grinding level) with the corresponding coefficients of determination $\left(R^{2}\right)$. The models are expressed in terms of coded values $((-1)(0),(+1))$

\begin{tabular}{llr}
\hline Response & Model equation & $R^{2}$ \\
\hline Extr. yield & $Y_{1}=24.95+0.76 X_{1}+1.94 X_{2}-0.73 X_{3}-0.64 X_{4}-0.59 X_{1} \cdot X_{3}-0.55 X_{2} \cdot X_{3}$ & 0.92 \\
Sugars & $Y_{2}=22.02+0.10 X_{1}+2.94 X_{2}-0.85 X_{3}-1.67 X_{4}-1.31 X_{1}^{2}-1.64 X_{1} \cdot X_{2}-1.22 X_{2} \cdot X_{3}$ & 0.82 \\
$\mathrm{GM}$ & $Y_{3}=11.68-0.33 X_{1}+2.61 X_{2}-1.28 X_{3}-1.12 X_{4}-1.62 X_{2}^{2}-1.71 X_{1} \cdot X_{2}-1.34 X_{2} \cdot X_{3}$ & 0.88 \\
$K_{\text {mix }, 405 \mathrm{~nm}}$ & $Y_{4}=0.494+0.021 X_{1}+0.038 X_{2}-0.040 X_{3}-0.008 X_{4}-0.017 X_{1} \cdot X_{3}-0.018 X_{2} \cdot X_{3}+0.011 X_{2} \cdot X_{4}-0.012$ & 0.89 \\
& $X_{3} \cdot X_{4}$ & \\
\hline
\end{tabular}

value (Table 1). Pareto chart (Fig. 1b) shows that temperature exerts a fundamental role regarding the extraction of carbohydrates from coffee matrix, through the increase of polysaccharide solubilisation with increasing temperatures. Regarding temperature, the linear term is positive and significant $(p<0.0001$, accounting for $43 \%$ of the data variability), as well as the interaction of this variable with time $\left(X_{1}\right)$ and $m / V$ ratio $\left(X_{3}\right)(p<0.05)$ (Fig. S3). The linear term of the parameter time is non-significant $(p>0.05)$, suggesting that in this system, prolonged time does not always result in an increase of the carbohydrate content in the extracts. However, at low temperature $\left(20^{\circ} \mathrm{C}\right)$, a considerable difference is observed between the extreme levels, i.e., longer extraction time (360 min, $18.3-21.5 \% \mathrm{w} /$ w) favors the carbohydrate extraction, comparing to shorter extraction time (10 min, $14.8-17.6 \% \mathrm{w} / \mathrm{w})$. This did not happen with the highest temperature level $\left(80^{\circ} \mathrm{C}\right.$, $10 \mathrm{~min}-21.6-29.6 \% \mathrm{w} / \mathrm{w} ; 360 \mathrm{~min}-18.9-29.7 \% \mathrm{w} / \mathrm{w})$, suggesting that with low temperatures, a prolonged time of extraction must be necessary to increase the sugars content. The quadratic term is significant $(p<0.05)$, suggesting a U-shape extraction profile for the sugars extraction in the conditions tested. Both $m / V$ ratio $\left(X_{3}\right)$ and grinding level $\left(X_{4}\right)$ linear terms were significant and have a negative impact, meaning that sugars content in the extract is lower with higher $m / V$ ratios and coarser particles. After removing the non-significant terms $(p>0.05)$, the full quadratic model $\left(R^{2}=0.82, p<0.0001\right)$ for the carbohydrate data fits a second-order polynomial equation, with non-significant lack-of-fit (Table 2). Moreover, the analysis of the initial extract shows that the roasted coffee has $48.8 \pm 3.7 \% \mathrm{w} / \mathrm{w}$ of sugars in its composition, in accordance with literature $[21,26]$. Considering the overall yield and sugars extraction, it was observed that $6.2-18.2 \%$ of coffee carbohydrates ends up in the extract, with a clear distinction in lower $\left(20^{\circ} \mathrm{C}, 6.2-10.4 \% \mathrm{w} / \mathrm{w}\right)$ and higher temperature levels $\left(80{ }^{\circ} \mathrm{C}, 9.5-18.2 \% \mathrm{w} / \mathrm{w}\right)$. Moreover, a positive linear correlation was verified $(r=0.77, p<0.0001)$ between extraction yield and sugars content within central composite design results, associating a higher extraction yield with an increase in the carbohydrates extraction.

\section{Sugars composition}

Regarding the sugar composition of coffee extracts, the single-factor experiments show that mannose, galactose, and arabinose were the sugar residues most abundant in the coffee extracts and the most affected by the operational parameters, once the range of variation among the conditions tested for rhamnose and glucose was quite low (1-3\%, expressed as relative \% $\%$ mol). The range of variation observed when tested different temperature for rhamnose (10\%), mannose $(21 \%)$, and galactose $(9 \%)$ was much greater than when considering the variation observed with the other parameters (1-5\%, for the three sugar residues), in analyses performed at $80{ }^{\circ} \mathrm{C}$. The study of central composite design shows that a $1.7-1.8$-fold variation may be observed for the three residues among all runs that represented $88-94 \%$ of sugar residues in all conditions tested. Among all polysaccharide structures present in roasted coffee matrix, cellulose is insoluble in the tested conditions, remaining in the coffee residue after extraction and filtration. Galactomannans (GM), composed by mannose and a small fraction of the galactose content, and type II arabinogalactans (AG), constituted mainly by galactose and arabinose, are the main polysaccharide present in the different coffee brews [5, 20]. GM (68-69\%) are the predominant polysaccharides in roasted coffee infusions, followed by AG (25-30\%) and with a much lower glucans content (2-6\%) [5]. As in this study, the coffee sample was always the same in all runs, the differences could only be due to the operational parameters used. Figure 2 shows the distribution of the GM and $\mathrm{AG}$ in relation to the carbohydrate content in each run. It is evident that AG content variation among all runs are lower $(7.5-12.0 \% \mathrm{w} / \mathrm{w})$ when compared to GM $(5.4-18.3 \%$ w/w). Thus, the GM extraction is more affected by operational parameters over the extraction conditions tested. This also suggests that roasted coffee powder, when subjected to water extractions, has AG that are readily solubilized and extracted quite independently of the conditions used.

The wide range of conditions tested, namely higher temperatures and longer extraction times, did not promote a significant increase of AG content. On the other hand, 
Fig. 2 Representation of the distribution of the coffee polysaccharides along the experiments: arabinogalactans (AG, $\% \mathrm{w} / \mathrm{w})$, galactomannans $(\mathrm{GM}$, $\left.Y_{3}, \% \mathrm{w} / \mathrm{w}\right)$ as part of the total sugars determined through the central composite design results presented in Table 1

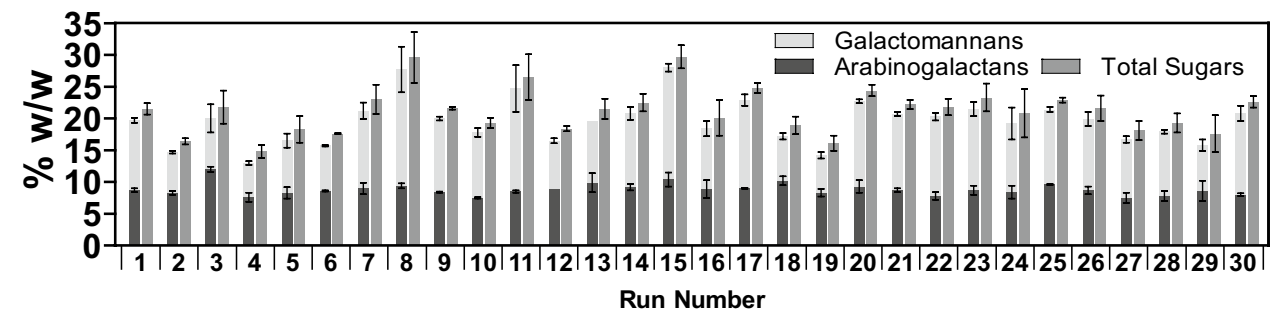

the variation of GM content can be linked to the observed increase in the carbohydrates extracted, once there is a positive and strong linear relationship between the content of GM and the sugars content in the extracts $(r=0.96$, $p<0.0001$ ), evidencing that the variation of sugar content among the extracts is related to the higher or lower extraction of GM.

Figure 1c shows that, as occurred in the extraction of carbohydrates, the linear term of temperature $\left(X_{2}\right)$ is the variable with clearly the main preponderance for higher relative GM content in the extracts. A significant model $(p<0.0001)$ fits the data for GM content $\left(R^{2}=0.88\right)$ after elimination of non-significant terms, exhibiting a non-significant lackof-fit (Table 2) and the response surface plots presented in Fig. 3 show how the factors studied affect the content of GM across the experimental design. The graphs are presented keeping constant the remaining two independent variables of each plot in the intermediate level of the design. At shorter extraction temperatures $\left(20^{\circ} \mathrm{C}\right)$, there is a clear difference on the relative GM content in the extract between using shorter extraction times (10 $\mathrm{min}, 5.4-7.1 \% \mathrm{w} / \mathrm{w}$ ) and longer extraction times (360 $\mathrm{min}, 7.7-9.7 \% \mathrm{w} / \mathrm{w})$. Thus, considering shorter extraction times, the GM represented only $36.5-40.3 \%$ of the extract carbohydrates, with a predominance of AG; while with longer extraction times, the GM content is similar or even slightly higher than AG in coffee brew extract. It can be concluded that lower temperatures promote mainly the extraction of AG, minimizing the amount of GM extracted. At lower temperatures, the amount of GM can be increased if prolonged extraction times are used. This allows to infer that the AG are more accessible in roasted coffee matrix than the GM, that require prolonged times at lower temperature for their extraction. At higher temperatures, the extraction of $\mathrm{GM}\left(80{ }^{\circ} \mathrm{C}, 7.0-18.3 \% \mathrm{w} / \mathrm{w}\right)$ was higher when comparing to lower temperatures $\left(20^{\circ} \mathrm{C}\right.$, 5.4-9.7\%w/w), even at shorter times (Fig. 3a). At the highest temperature and during short times, the GM represented the major polysaccharide of the extract $(53.7-61.8 \% \mathrm{w} / \mathrm{w})$. The effect of mass ratio and grinding level over time (Fig. 3b, c) shows that once the temperature was constant, the differences in GM extraction were slight. Nevertheless, when extraction was performed during prolonged times, the relative content of GM decreased, becoming the AG the predominant polysaccharide, only when high $m / V$ ratio is used
(Fig. 3d). While with lower temperatures, a prolonged time allows to extract more GM, it is possible that at higher temperatures and high $m / V$ ratio, a GM solvent saturation could occur not enabling the extraction of GM. The occurrence of interaction/adsorption of the GM with the cellulose present in the matrix is also probable [30,31], preventing their extraction. Thus, higher temperatures and prolonged times, especially using higher $m / V$ ratio, should be avoided for GM extraction. The extraction of GM may be reduced if coarser particles were used when fixing the time and $m / V$ ratio, while varying the temperature (Fig. 3e). When the temperature and time were constant, at lower $m / V$ ratio and grinding level, the GM extraction was slightly enhanced (Fig. 3f).

The results obtained show that the extraction of coffee powder at high temperatures (in conventional systems, not comparable to industrial extraction performed at extreme temperatures way over $100{ }^{\circ} \mathrm{C}$ ) may produce a coffee extract with low amount of GM. According to literature, high temperatures originates extracts and brews with GM as the main polymer present [5, 21]. However, this occurs only for short periods of time and low mass-volume ratios, as used to prepare home coffee brews. Performing the extraction at $80{ }^{\circ} \mathrm{C}$ during prolonged extraction times and using a high mass-volume ratio, the extracts have a predominance of AG over GM. The different GM/AG ratio verified all over the design space may also be associated with the beverage properties, such as the viscosity of coffee solutions. The higher amount of GM in the coffee extracts was shown to be associated with the increase in kinematic viscosity (Table 1) through a strong and positive linear relationship $(r=0.95, p<0.001)$. The carbohydrates in coffee brews and mainly GM act as viscosity improvers, stabilizing the foam in espresso coffee [32]. On the other hand, using low temperatures, there is a predominance of AG in the coffee extracts, in accordance with the composition of cold coffee brews, promoting the occurrence of polysaccharide structures with immune-modulating activity [33]. Indeed, AG have immunostimulatory activity dependent on structural features, as terminally linked arabinose residues, as shown in instant coffee fractions [34], highlighting the influence of the different technological parameters to obtain extracts rich in polysaccharides with different properties suitable for distinct applications. 
(a)

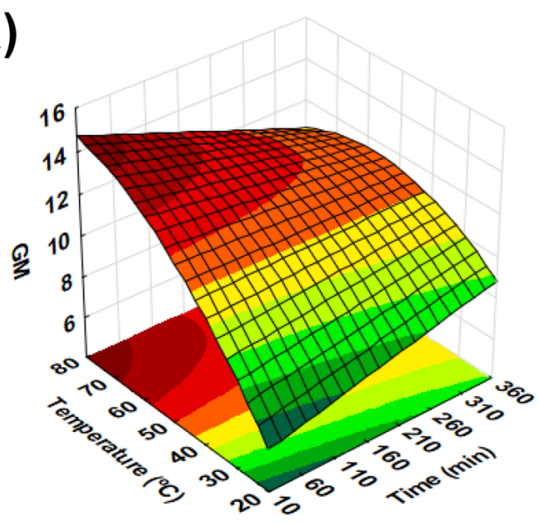

(c)

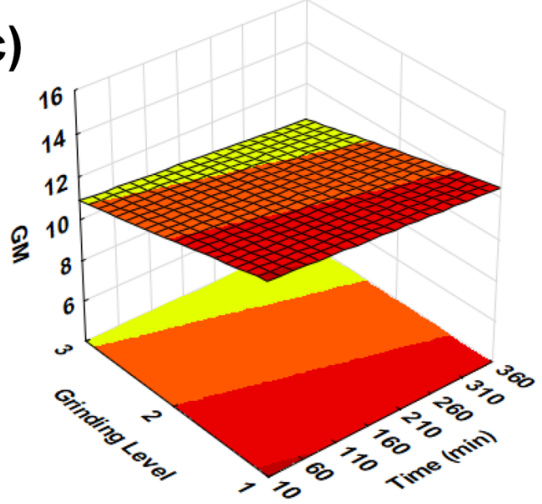

(e)

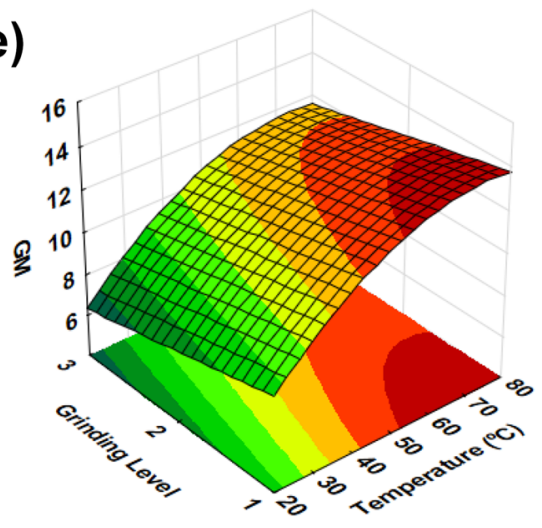

(b)

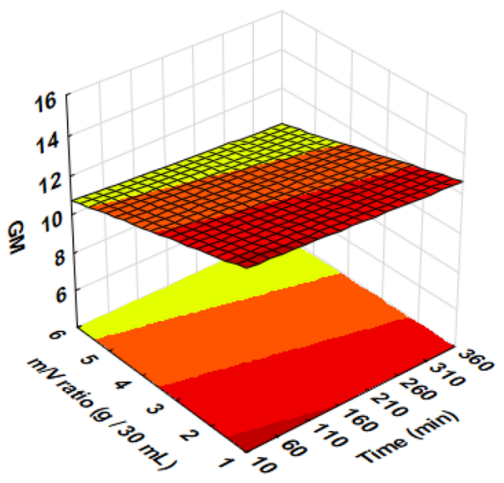

$<13$

$<11$

$<9$

$<7$

\section{(d)}

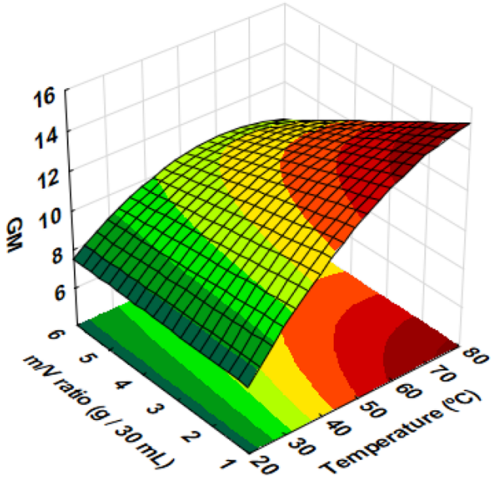

$<13$

$<12$

$<11$

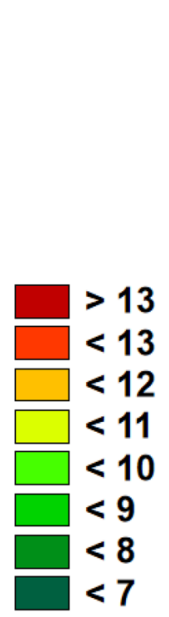

Fig. 3 Response surface plots (3D) of the model developed representing the content of galactomannans $\left(Y_{3}, \% \mathrm{w} / \mathrm{w}\right)$ in the coffee extracts showing the effect of the different extraction parameters. In each plot,

The roasted coffee used is composed by $45.5,28.4,19.1$ and $6.5 \% \mathrm{~mol}$ of mannose, galactose, glucose, and arabinose, in accordance with literature [4]. This allows to estimate a content of $23.6 \pm 1.6 \% \mathrm{w} / \mathrm{w}$ for $\mathrm{GM}$ and $15.5 \pm 1.6 \% \mathrm{w} / \mathrm{w}$ for

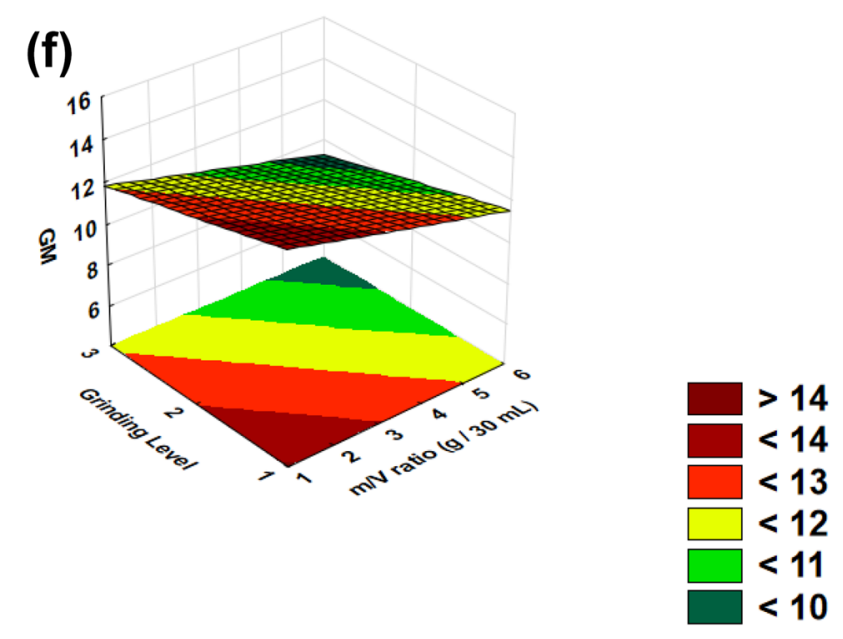

two of the independent variables were maintained at their intermediate level: time $\left(X_{1}\right)-185 \mathrm{~min}$; temperature $\left(X_{2}\right)-50{ }^{\circ} \mathrm{C} ; \mathrm{m} / V$ ratio $\left(X_{3}\right)$-3.5 g/30 mL; $\left(X_{4}\right)$ - grinding level-level 2

AG. Thus, $5-22 \%$ w/w of GM and $10-20 \%$ w/w of AG are extracted to the coffee extracts with the conditions used, corresponding to nearly only $20 \% \mathrm{w} / \mathrm{w}$ of the coffee powder polysaccharides extracted in the conditions tested. Based 
on the data obtained, higher temperatures are needed for a complete extraction of the coffee polysaccharides. This is in accordance with the use of microwave-assisted extraction at temperatures reaching $200{ }^{\circ} \mathrm{C}$ for a complete extraction of coffee polysaccharides from coffee matrix [35].

\section{$K_{\text {mix, }} 405 \mathrm{~nm}$}

The single-factor experiments show that the range of variation for $K_{\text {mix }} 405 \mathrm{~nm}$ values varying temperature ( 0.15 , the difference between maximum and minimum value) was slightly higher than the occurred with mass-volume ratio (0.12), following the observed with time (0.08) and with grinding level (0.03) (Supplementary Material Table S1). This suggests that temperature and mass-volume ratio can greatly influence the brown color of the extracts obtained due to the increase of brown compounds (melanoidins) or due to the dilution of such compounds with increasing extraction of colorless structures while maintaining the content of the brown ones. Melanoidins are brown compounds formed during the roasting process through Maillard reaction involving carbohydrates, proteins and phenolic compounds. The brown color dilution factor measured at $405 \mathrm{~nm}$ is indicative of the melanoidins content, ranging from 0.40 to $0.64 \mathrm{~mL} \mathrm{mg}^{-1}$ $\mathrm{cm}^{-1}$, values comparable with literature reports for coffee brews [26, 36]. The ANOVA and Pareto graph (Fig. 1d) show that the linear terms of $m / V$ ratio $\left(X_{3}\right)$ and temperature $\left(X_{2}\right)$ were the main effects influencing $K_{\text {mix }} 405 \mathrm{~nm}$ at a similar level, explaining 33 and $30 \%$ of the variability observed. The higher temperatures and lower $m / V$ ratios lead to browner coffee extracts, suggesting higher melanoidins extraction. The linear term linked to time $\left(X_{1}\right)$ also significantly affects the $K_{\text {mix }, 405 \mathrm{~nm}}$, but to a lower extent, meaning more browner with longer extraction times. The browning of the extracts over the conditions studied may be linearly described by a significant model $(p<0.0001)$, with high determination coefficient $\left(R^{2}=0.89\right)$ and non-significant lack-of-fit (Table 2 and response surface plots of Fig. 4). Neither the linear nor the quadratic terms of the variable grinding level $\left(X_{4}\right)$ exert a significant effect on $K_{\text {mix }} 405 \mathrm{~nm}$, explaining the slight variation observed when the grinding degree varied (Fig. 4c, e, f). Longer extraction times (Fig. 4a-c) and temperatures (Fig. 4a, d, e) increase the browning of the extracts obtained, in accordance with literature [10]. Moreover, it seems that the effect of $m / V$ ratio is more pronounced when longer extraction times (Fig. 4b) or higher extraction temperatures (Fig. 4d) were applied, explaining the significance of such interactions $\left(X_{1} \cdot X_{3}, X_{2} \cdot X_{3}\right)$. Thus, maintaining constant the temperature of extraction, the extract become browner if longer extraction times and lower mass-volume ratio are applied, as well as higher $K_{\text {mix, } 405 \mathrm{~nm}}$ values are obtained when higher temperature accompanied a lower mass-volume ratio fixing the time of extraction. The fact that a higher mass-volume ratio is associated with a lower $K_{\text {mix }, 405 \mathrm{~nm}}$ seems to be explained by the preferential extraction of colorless compounds, as occurred with AG, hindering the extraction of the more browned ones. A positive correlation between the extraction yield and the $K_{\text {mix }} 405 \mathrm{~nm}$ values of central composite design $(r=0.81, p<0.0001)$ is also perceived, showing that the increase of extracted compounds from the coffee powder has a preferential contribution of brown compounds.

\section{Caffeine and 5-CQA}

The analysis of caffeine content in the single-factor experiments shows that caffeine content in the extract has the higher variation when testing temperature $(2.1 \%)$ compared to all the other variables $(0.5-1.1 \%)$ (Supplementary Material Table S1). From the analysis through the central composite design, the caffeine proportion in the extract varied from 7.1 to $9.7 \% \mathrm{w} / \mathrm{w}$ (Table 1 ), in accordance with the relative content of caffeine in coffee brews [3, 7, 8]. The statistical analysis showed that it is possible to significantly model the percentage of caffeine in the coffee extract $(p<0.0001$, $R^{2}=0.89$ and non-significant lack-of-fit), with the temperature exerting the most significant, and negative effect. When crossing the data from extraction yield and the caffeine content in the extract, a value $(2.2 \pm 0.1 \% \mathrm{w} / \mathrm{w})$ correspondent to the amount of caffeine found in the roasted coffee in the initial sample $(1.9 \pm 0.2 \% \mathrm{w} / \mathrm{w})$ was observed, which is in accordance with literature reports $(0.8-2.6 \% \mathrm{w} / \mathrm{w})$ for different species and roasting degrees [37-39]. Nevertheless, it should be noted that the analysis of the content in the coffee powder presupposes an extraction step, a coffee brew itself, that may influence the higher or lower quantification of caffeine in the roasted coffee. However, it can be concluded that in the conditions tested, the caffeine was almost or totally extracted. Literature reports that the solubility of caffeine increased widely with temperature, ranging from 1.46 to $19.23 \mathrm{~g}$ per $100 \mathrm{~g}$ water at 20 and $80^{\circ} \mathrm{C}$, respectively, the extreme values used in this study, becoming even more soluble at $100{ }^{\circ} \mathrm{C}(66.6 \% \mathrm{w} / \mathrm{w})$ [40]. Considering the caffeine content present in the roasted coffee and the volume of water used $(30 \mathrm{~mL})$, all extraction experiments took place in conditions below these limits. Indeed, in several conventional extraction methods, the extraction of caffeine reaches $81-100 \%$ [2,9]. The extraction times performed in these experiments should allow the dissolution of all caffeine from the coffee matrix, even considering the shorter extraction time (10 min). Hence, the variations observed in the relative mass content of caffeine in the extract should be related to the differences observed with the contribution of other compounds in the extract than with the content of caffeine itself. Thus, a higher or lower proportion of caffeine in the extract is not related to an increase in caffeine extraction, 
(a)

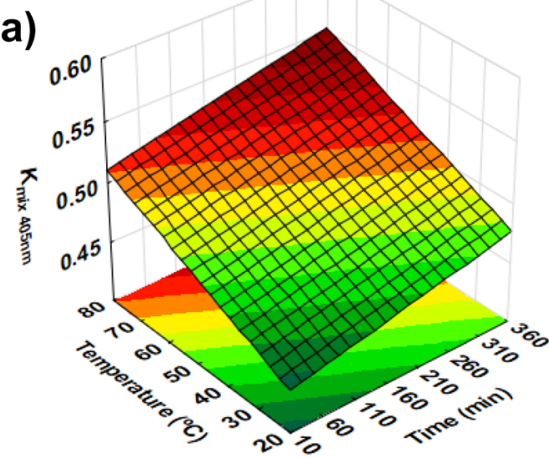

(c)

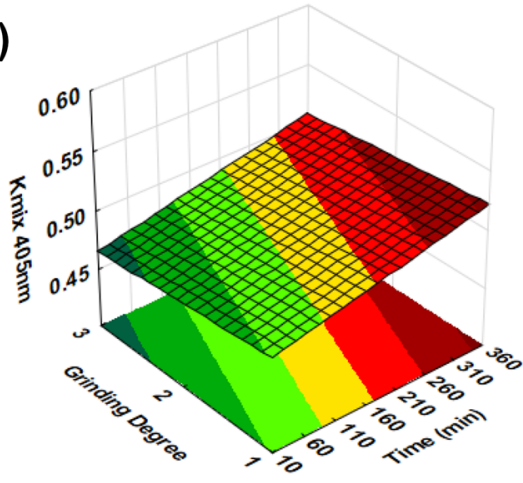

(e)

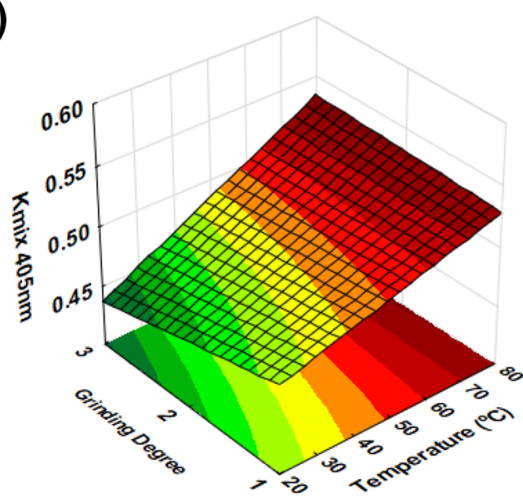

(b)

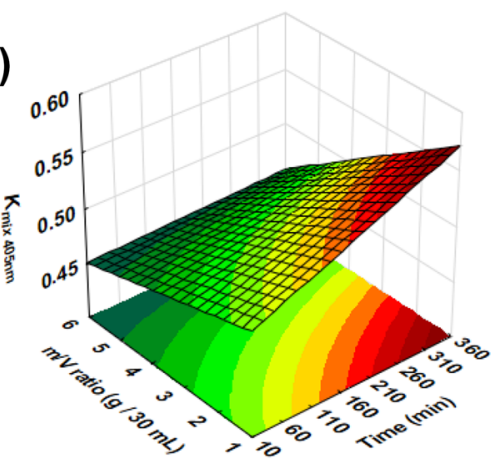

(f)

(d)
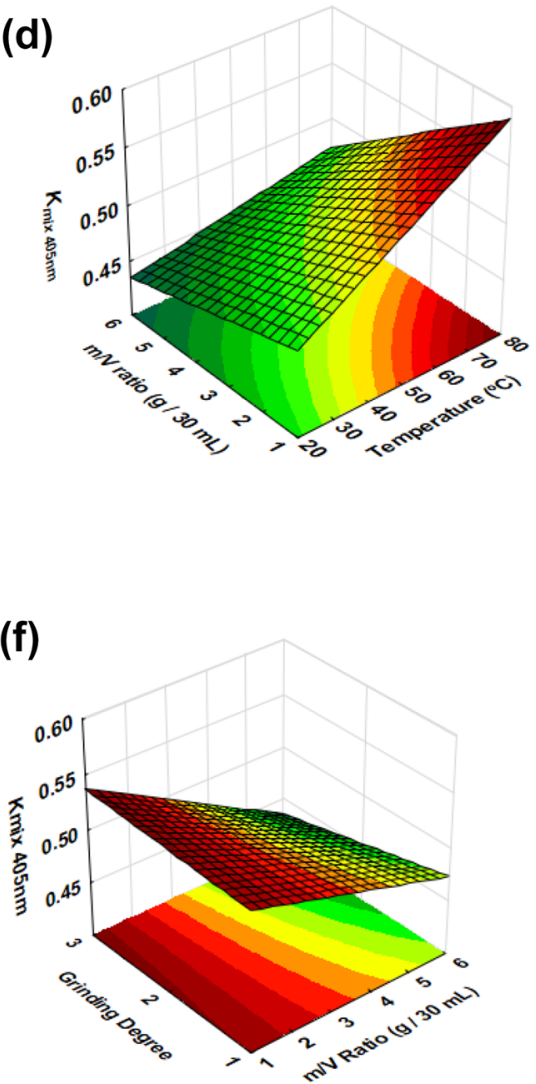

$>0.52$

$<0.52$

$<0.50$

$<0.48$

$<0.46$

$<0.44$
Fig. 4 Response surface plots (3D) of the model developed representing the variation of $K_{\text {mix, } 405 \mathrm{~nm}}$ values $\left(Y_{4}, \mathrm{~mL} \mathrm{mg}^{-1} \mathrm{~cm}^{-1}\right)$ in the coffee extracts showing the effect of the different extraction param-

but with the dilution or concentration of such quantity of caffeine in the overall mass of the extract. In fact, the caffeine content may be negatively correlated with the sugars content in the extract $(r=-0.80, p<0.0001)$, suggesting eters. In each plot, two of the independent variables were maintained at their intermediate level: time $\left(X_{1}\right)-185 \mathrm{~min}$; temperature $\left(X_{2}\right)$ $50{ }^{\circ} \mathrm{C} ; \mathrm{m} / V$ ratio $\left(X_{3}\right)$ - $3.5 \mathrm{~g} / 30 \mathrm{~mL} ;\left(X_{4}\right)$ - grinding level—level 2

that higher/lower sugars content leads to a dilution/concentration effect of caffeine in the extract. On the other hand, due to the different mass-volume ratio, it can be observed also a large range of concentration of caffeine, from 0.6 to 
$4.5 \mathrm{mg} \mathrm{mL}^{-1}$, representing from 19 to $136 \mathrm{mg}$ in the $30 \mathrm{~mL}$ used in all the experiments due to different mass of coffee powder from where the caffeine was extracted. This wide variability is also reported in the different homemade coffee brews (1.4-7.9 $\mathrm{mg} \mathrm{mL}^{-1}$ ), even within the same method $[41,42]$. Thus, this concept of the higher extractability of caffeine from coffee powder, when compared to the other components, should be taken into consideration when determining the caffeine content in coffee brews.

The chlorogenic acid present at the highest level in roasted coffee samples and coffee brews is the 5-CQA isomer [38]. The analysis of 5-CQA revealed a comparable pattern of extraction with that observed for caffeine. The proportion of this compound in the overall extracts varied from 1.9 to $2.9 \% \mathrm{w} / \mathrm{w}$, in accordance with the verified in coffee infusion brews $(2.9 \% \mathrm{w} / \mathrm{w})$ or even different methods $(1.8-2.4 \% \mathrm{w} / \mathrm{w})[43,44]$. However, considering the extraction yield, the content of 5-CQA extracted represented $0.55-0.69 \%$, a value comparable to the initial content in the powder $(0.7 \pm 0.1 \% \mathrm{w} / \mathrm{w})$, meaning that the compound was fully extractable. Literature also shows similar values for roasted coffee samples $(0.7-1.5 \% \mathrm{w} / \mathrm{w})[39,43]$. During the experiments, it was possible to obtain coffee brews with $0.2-1.3 \mathrm{mg} \mathrm{mL}^{-1}$ of 5-CQA but such differences arose from the different amount of coffee used for the extraction. Nevertheless, it is possible to develop a significant model $\left(p<0.001, R^{2}=0.88\right.$, data not shown) based on 5-CQA content in the extract where temperature exerted a significant and negative effect due to the higher relative extraction of other compounds. Therefore, its applicability is limited once the modulation should be more based on the other compounds than properly with 5-CQA.

\section{Concluding remarks}

This study analyzed the effect of several operational factors in the roasted coffee extraction process highlighting the main effects and enabling the development of statistically significant models that describe the system. It was showed that temperature is the most significant effect regarding the overall extraction yield and sugars content and composition. A maximum of $29.9 \% \mathrm{w} / \mathrm{w}$ of the compounds present in the roasted coffee may be extracted. The estimation of the two main polysaccharides in coffee (galactomannans (GM) and arabinogalactans (AG)), showed that, while the variation of $\mathrm{AG}$ content across the experimental design was low $(7.5-12.0 \% \mathrm{w} / \mathrm{w})$, the variation concerning GM was substantial $(5.4-18.3 \% \mathrm{w} / \mathrm{w})$. The extraction of GM from coffee powder increases with increasing temperatures, while the extraction of AG is not so dependent on temperature. When using high temperatures, the AG are the main polysaccharides extracted if longer times and high $m / V$ ratio are used.
The increase in GM content is reflected in a higher viscosity associated with brews prepared with such extracts. The overall mass extraction yield seems to be related to the brown color of the coffee extracts (or the solutions prepared with them), exerting in such case $m / V$ ratio and temperature the main significant effects. Caffeine and 5-CQA are extensively extracted in the conditions tested, while their content in each extract varied due to the concentration/dilution in relation to other extracted compounds. Although, temperature is the main factor affecting the system, the other parameters should also be considered as there are some interactions between coffee extraction variables. Thus, when studying extraction processes, a comprehensive study of how operational variables affect the system should be performed. Regarding coffee extraction, namely, infusion methods, this study shows that it is possible to modulate the conditions of the coffee extraction to obtain preferentially a desired compound/group of compounds, obtaining extracts with different compositions and, consequently, properties, either biological or sensorial.

Acknowledgements Thanks are due to the University of Aveiro and FCT/MCT for the financial support for the QOPNA research Unit (FCT UID/QUI/00062/2019) through national founds and, where applicable, co-financed by the FEDER, within the PT2020 Partnership Agreement, and to the Portuguese NMR Network. Guido R. Lopes and Cláudia P. Passos were supported by individual doc (SFRH/BD/104855/2014) and post-doc (SFRH/BDP/107881/2015) grants by FCT, respectively.

\section{Compliance with ethical standards}

Conflict of interest The authors declare no conflict of interests.

Compliance with ethics requirements This article does not contain any studies with human or animal subjects.

\section{References}

1. Gloess AN, Schönbächler B, Klopprogge B, D’Ambrosio L, Chatelain K, Bongartz A, Strittmatter A, Rast M, Yeretzian C (2013) Comparison of nine common coffee extraction methods: instrumental and sensory analysis. Eur Food Res Technol 236(4):607-627

2. Illy A, Viani R (2005) Espresso coffee: the science of quality. Elsevier, Amsterdam

3. Maeztu L, Andueza S, Ibañez C, Paz de Peña M, Bello J, Cid C (2001) Multivariate methods for characterization and classification of espresso coffees from different botanical varieties and types of roast by foam, taste, and mouthfeel. J Agric Food Chem 49(10):4743-4747

4. Oosterveld A, Voragen AGJ, Schols HA (2003) Effect of roasting on the carbohydrate composition of Coffea arabica beans. Carbohydr Polym 54(2): 183-192

5. Nunes FM, Coimbra MA (2001) Chemical characterization of the high molecular weight material extracted with hot water from green and roasted arabica coffee. J Agric Food Chem 49(4):1773-1782 
6. von Blittersdorff M, Klatt C (2017) Chapter 13 - The Grind-Particles and Particularities. In: Folmer B (ed) The Craft and Science of Coffee. Academic Press, Amsterdam

7. Andueza S, Vila MA, Paz de Peña M, Cid C (2007) Influence of coffee/water ratio on the final quality of espresso coffee. J Sci Food Agric 87(4):586-592

8. Andueza S, de Peña MP, Cid C (2003) Chemical and sensorial characteristics of espresso coffee as affected by grinding and torrefacto roast. J Agric Food Chem 51(24):7034-7039

9. Petracco M (2001) Technology IV: beverage preparation: brewing trends for the new millennium. In: Clarke RJ, Vitzthum OG (eds) Coffee: recent developments. Blackwell Science, London

10. Merritt MC, Proctor BE (1959) Extraction rates for selected components in coffee brew. J Food Sci 24(6):735-743

11. Parenti A, Guerrini L, Masella P, Spinelli S, Calamai L, Spugnoli P (2014) Comparison of espresso coffee brewing techniques. J Food Eng 121:112-117

12. Moroney KM, Lee WT, O'Brien SBG, Suijver F, Marra J (2015) Modelling of coffee extraction during brewing using multiscale methods: An experimentally validated model. Chem Eng Sci 137:216-234

13. Melrose J, Roman-Corrochano B, Montoya-Guerra M, Bakalis S (2018) Toward a new brewing control chart for the 21st century. J Agric Food Chem 66(21):5301-5309

14. Voilley A, Simatos D (1979) Modeling the solubilization process during coffee brewing. J Food Process Eng 3(4):185-198

15. Espinoza-Pérez JD, Vargas A, Robles-Olvera VJ, Rodríguez-Jimenes GC, García-Alvarado MA (2007) Mathematical modeling of caffeine kinetic during solid-liquid extraction of coffee beans. J Food Eng 81(1):72-78

16. Ribeiro JS, Teófilo RF, Augusto F, Ferreira MMC (2010) Simultaneous optimization of the microextraction of coffee volatiles using response surface methodology and principal component analysis. Chemom Intell Lab 102(1):45-52

17. Barbosa HMA, de Melo MMR, Coimbra MA, Passos CP, Silva CM (2014) Optimization of the supercritical fluid coextraction of oil and diterpenes from spent coffee grounds using experimental design and response surface methodology. J Supercrit Fluid 85:165-172

18. Ballesteros LF, Ramirez MJ, Orrego CE, Teixeira JA, Mussatto SI (2017) Optimization of autohydrolysis conditions to extract antioxidant phenolic compounds from spent coffee grounds. J Food Eng 199:1-8

19. Ballesteros LF, Teixeira JA, Mussatto SI (2014) Selection of the solvent and extraction conditions for maximum recovery of antioxidant phenolic compounds from coffee silverskin. Food Bioprocess Tech 7(5):1322-1332

20. Lopes GR, Ferreira AS, Pinto M, Passos CP, Coelho E, Rodrigues C, Figueira C, Rocha SM, Nunes FM, Coimbra MA (2016) Carbohydrate content, dietary fibre and melanoidins: composition of espresso from single-dose coffee capsules. Food Res Int 89:989-996

21. Oosterveld A, Harmsen JS, Voragen AGJ, Schols HA (2003) Extraction and characterization of polysaccharides from green and roasted Coffea arabica beans. Carbohydr Polym 52(3):285-296

22. Nunes FM, Coimbra MA (2002) Chemical characterization of galactomannans and arabinogalactans from two arabica coffee infusions as affected by the degree of roast. J Agric Food Chem 50(6):1429-1434

23. Nunes FM, Coimbra MA (2002) Chemical characterization of the high-molecular-weight material extracted with hot water from green and roasted robusta coffees as affected by the degree of roast. J Agric Food Chem 50(24):7046-7052

24. Passos CP, Rudnitskaya A, Neves JMMGC, Lopes GR, Evtuguin DV, Coimbra MA (2019) Structural features of spent coffee grounds water-soluble polysaccharides: towards tailor-made microwave assisted extractions. Carbohydr Polym 214:53-61
25. Nunes FM, Cruz ACS, Coimbra MA (2012) Insight into the mechanism of coffee melanoidin formation using modified "in Bean" models. J Agric Food Chem 60(35):8710-8719

26. Bekedam EK, Schols HA, van Boekel MAJS, Smit G (2006) High molecular weight melanoidins from coffee brew. J Agric Food Chem 54(20):7658-7666

27. Mestdagh F, Glabasnia A, Giuliano P (2017) Chapter 15-the brew-extracting for excellence. In: Folmer B (ed) The craft and science of coffee. Academic Press, Amsterdam

28. Angeloni G, Guerrini L, Masella P, Innocenti M, Bellumori M, Parenti A (2019) Characterization and comparison of cold brew and cold drip coffee extraction methods. J Sci Food Agric 99(1):391-399

29. Clarke RJ, Macrae R (1987) Coffee: vol. 2: technology. Elsevier, London

30. Wang X, Li K, Yang M, Wang J, Zhang J (2017) Hydrolyzability of mannan after adsorption on cellulose. Cellulose 24(1):35-47

31. Newman RH, Hemmingson JA (1998) Interactions between locust bean gum and cellulose characterized by $13 \mathrm{C}$ n.m.r. spectroscopy. Carbohydr Polym 36(2):167-172

32. Nunes FM, Coimbra MA (1998) Influence of polysaccharide composition in foam stability of espresso coffee. Carbohydr Polym 37(3):283-285

33. Shin K-S (2017) The chemical characteristics and immune-modulating activity of polysaccharides isolated from cold-brew coffee. Prev Nutr Food Sci 22(2):100-106

34. Ferreira SS, Passos CP, Cepeda MR, Lopes GR, Teixeira-Coelho M, Madureira P, Nunes FM, Vilanova M, Coimbra MA (2018) Structural polymeric features that contribute to in vitro immunostimulatory activity of instant coffee. Food Chem 242:548-554

35. Passos CP, Moreira ASP, Domingues MRM, Evtuguin DV, Coimbra MA (2014) Sequential microwave superheated water extraction of mannans from spent coffee grounds. Carbohydr Polym 103:333-338

36. Bekedam EK, Loots MJ, Schols HA, Van Boekel MAJS, Smit G (2008) Roasting effects on formation mechanisms of coffee brew melanoidins. J Agric Food Chem 56(16):7138-7145

37. Hečimović I, Belščak-Cvitanović A, Horžić D, Komes D (2011) Comparative study of polyphenols and caffeine in different coffee varieties affected by the degree of roasting. Food Chem 129(3):991-1000

38. Fujioka K, Shibamoto T (2008) Chlorogenic acid and caffeine contents in various commercial brewed coffees. Food Chem 106(1):217-221

39. Moreira ASP, Nunes FM, Simões C, Maciel E, Domingues P, Domingues MRM, Coimbra MA (2017) Data on coffee composition and mass spectrometry analysis of mixtures of coffee related carbohydrates, phenolic compounds and peptides. Data Brief 13:145-161

40. Macrae R (1985) Nitrogenous components. In: Clarke RJ, Macrae $\mathrm{R}$ (eds) Coffee: volume 1: chemistry. Springer, Dordrecht

41. Ludwig IA, Mena P, Calani L, Cid C, Del Rio D, Lean MEJ, Crozier A (2014) Variations in caffeine and chlorogenic acid contents of coffees: what are we drinking? Food Funct 5(8):1718-1726

42. Crozier TWM, Stalmach A, Lean MEJ, Crozier A (2012) Espresso coffees, caffeine and chlorogenic acid intake: potential health implications. Food Funct 3(1):30-33

43. Bekedam EK, Schols HA, Van Boekel MAJS, Smit G (2008) Incorporation of chlorogenic acids in coffee brew melanoidins. J Agric Food Chem 56(6):2055-2063

44. López-Galilea I, De Peña MP, Cid C (2007) Correlation of selected constituents with the total antioxidant capacity of coffee beverages: influence of the brewing procedure. J Agric Food Chem 55(15):6110-6117

Publisher's Note Springer Nature remains neutral with regard to jurisdictional claims in published maps and institutional affiliations. 


\section{Affiliations}

\section{Guido R. Lopes ${ }^{1} \cdot$ Cláudia P. Passos $^{1} \cdot$ Carla Rodrigues $^{2} \cdot$ José A. Teixeira $^{3} \cdot$ Manuel A. Coimbra $^{1}$}

1 QOPNA \& LAQV-REQUIMTE, Department of Chemistry, University of Aveiro, 3810-193 Aveiro, Portugal

3 Centre of Biological Engineering, University of Minho, Campus de Gualtar, 4710-057 Braga, Portugal

2 Diverge, Grupo Nabeiro Innovation Center, Alameda dos Oceanos 65, 1.1, 1990-208 Lisbon, Portugal 